\title{
Lo-Res: Architectural Strategies of Localized Resilience
}

\author{
MICHAEL JEFFERSON \& SUZANNE LETTIERI \\ Cornell University
}

Rather than considering coastal architecture and flood defense infrastructure as having incompatible agendas, this paper argues for a study of new architectural and infrastructural hybridizations with a focus on the underlying systems that not only determine manmade fortifications that control the movement of and access to water but also offer discrete spaces for inhabitation. A study of water management infrastructural types, paired with vulnerable, remote, and unprotected coastal and riverine sites, anticipate alternative methods of resilience that serve to mediate human inhabitation in flood-threatened territories. What strategies of resilience can we establish that go beyond the typical (that accommodate flooding, flee from it, and fortify against it) and begin to incorporate dynamic characteristics of the physical environment with architectural form? The projects discussed in this paper explore these questions and are a product of the Cornell University architecture studio Lo-Res: Architectural Scales of Localized Resilience conducted during Spring 2016.

Faced with rising sea levels and extreme flooding, contemporary approaches to flood defense have typically consisted of massive infrastructures for the protection of cities or even more tremendous assemblages that provide control at the territorial scale. On one hand, these strategies offer relief from fears of flooding and ameliorate the concerns of designers: in being protected beyond the (sea) wall, architecture requires little to no adaptation of its physical form. But these strategies present the challenges epitomized by hard infrastructures that are conventional and deterministic. Namely, they favor modernist approaches to citymaking that consist of discrete elements lacking the ability to accommodate change. In particular, through the use of barriers and voided territory, these forms alienate coastal areas from inhabited urban zones, sequestering the city from the context that would give it character and serving as one-size fits all strategies that ignore climatic and environmental qualities specific to site.
When these infrastructures fail, often an equally absolutist stance is taken: that of coastal retreat, in which current zoning policies call for the evacuation of coastal areas. Caught between an ultimatum of fortification or retreat, designers have focused on alternative tactics of living with water. In leaning away from hard infrastructures such as sea walls, berms, and dikes, softer infrastructures that blur the line between land and water have been implemented which incorporate temporal qualities, are multiple and iterative, and absorb disturbance. ${ }^{1}$ The conceptual shift toward more integrated negotiations with water has triggered a sequence of proposals that have rightfully centered around efforts to make urban areas more resilient through robust and inventive infrastructures. ${ }^{2}$ However, the philosophy of collective water management is in contrast with the American notion of individual ownership exemplified in the tenets of insurance policies that rely on case-by-case claim resolution in suburban and rural areas. As such, policy structures contradict innovative design tactics and prevent coordinated systematic infrastructural-urban planning efforts.

In the U.S., urban and territorial-scale infrastructures yield to the expansive distance of the East and Gulf Coasts, resulting in the absence of large-scale defenses for areas peripheral to cities. This gap in infrastructural protection particularly affects remote regions and otherwise marginalized areas, leaving isolated architectures to fend for themselves. The reverberations of these holes in flood defense and increasing environmental degradation are evidenced by zoning policies which set out standards for building within flood zones. ${ }^{3}$ Left to their own devices, the resulting architecture acquires monstrous characteristics. For instance, zoning laws at times squash houses between conventional allowances for maximum height and extraordinarily high minimum elevations for flood protection, often resulting in stilted pancaked massings. The outcome of this intractable negotiation between policy and climate change has been revealed en masse in housing along the East and Gulf coasts where architecture evolves, deforms, and reconstitutes itself along the new elevated horizon and forms new relationships with the ground.

Responding to the collisions of policy, infrastructure, and architecture and building on current flood defense tactics, one might suggest an alternative strategy in developing techniques that can be described 

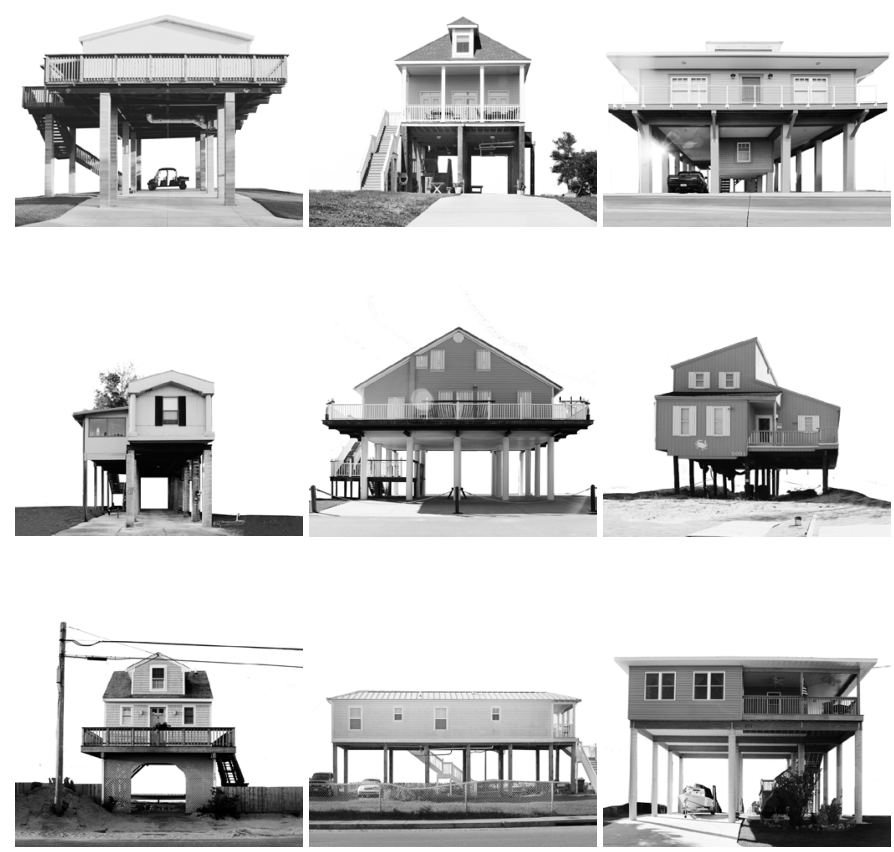

Figure 1: Images from (post)line, a research project on architecture's response to rising sea-levels along America's East and Gulf Coast by Michael Jefferson and Suzanne Lettieri (JeLe), 2013.

as lo-res: that is to say, strategies of localized resilience that exist predominantly at an architectural-scale. Doing so asks whether it is is possible to do more than defend but also incorporate everyday practice, beginning first with infrastructure conceived at a smaller scale and working from the bottom-up to create a coordinated system of architecture-infrastructure hybrids. By hybridizing what is typically static and homogenous with that which accommodates environmental change and dynamic programmatic use, we may reinject what Alexander D'Hooge calls the objecthood of infrastructure that avoids a strict systemized and functionalist approach and embraces a cultural and material presence of infrastructure. ${ }^{4}$

In searching for a site to experiment with a hybridization strategy, it is worth considering that isolated architectures that fend for themselves in flood-prone territories are not limited to the U.S. Rather, these housing scenarios begin to resemble those that are pervasive in marginalized coastal regions throughout the world. To avail itself of opportunities latent in other outlying and flood-prone contexts, particularly where architecture is expected to extend beyond the burden of flood defense, the Cornell University advanced travel studio Lo-Res: Architectures of Localized Resilience confronted flood defense strategies at an architectural-scale and sited projects in Suriname, where by definition the local condition is synonymous with flooding and isolation. Exacerbated by climate change, the studio was charged with generating solutions that mediated the volatile conditions of unstable and unreliable landscapes in Suriname with architectural solutions that took on the qualities of water management infrastructures and vice versa.
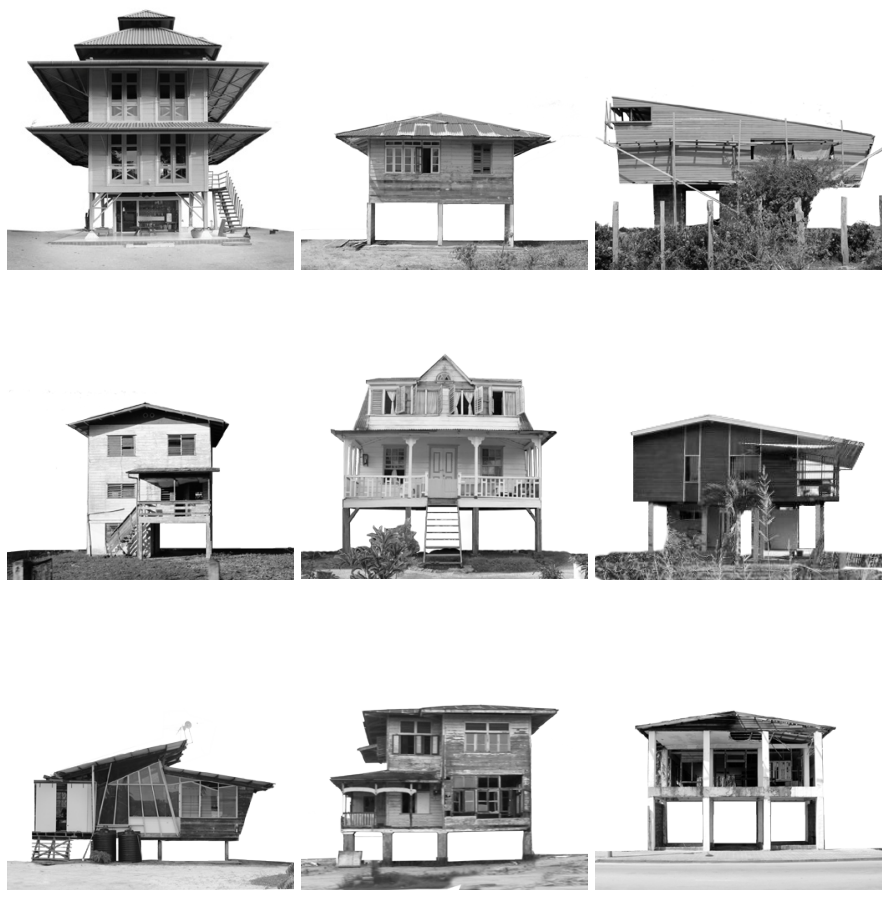

Images from Suriname, 2016.

Suriname, a sparsely occupied country and the smallest in South America, echoes the remote or marginalized conditions prevalent in the U.S. but to an extreme. It is defined by its unspoiled natural resources, including the largest slice of protected rainforest in the world, and it's minimal infrastructural systems, wherein its rivers far outnumber its roads and serve as the main conduits in the country's interior. Thus, if in the U.S. lo-res tactics concern peripheral and marginalized territories such as coastal suburban and rural contexts, in Suriname they address the hinterland.

Yet what differentiates Suriname from locations with similar conditions is its historical relationship with water management and prevalent infrastructure despite remote conditions. The country continues to sustain cultural, political, and economic links to the Netherlands since its independence in 1975. As a result, evidence of Dutch engineering feats such as the dikes, dams, and canals to mitigate flooding are pervasive. Yet increased sea level rise, expanding flood prone territories, high annual precipitation totals, and maintenance costs often supersede these engineered solutions. Despite systemic flooding, water is among the most valuable of Suriname's natural resources and has come to play an important role in its burgeoning ecotourism industry which relies on coastal and riparian areas both as destinations and conduits for access to the country's vast interior rainforest. Yet, the desire for proximity to water is often times at odds with the vulnerability that it entails. This is engendered by the both//and conditions it purports: opportunity// threat, conduit//boundary, leisure//industry, and serves as an ideal test bed for strategies that combine the functionality of resilience with the experiential qualities of architecture. 
The Lo-Res studio works between the conditions of large scale infrastructures and the smaller scales of architecture and between deterministic functionalist agendas and and dynamic potentials of the physical environment. Through the creation a catalog of the typologies of flood defense, a spectrum was introduced that ranged from structures and landscapes that avoid, absorb, and defend against flooding and from the mechanical to the natural. Each was studied and scrutinized not only to understand how they might work, but also to consider alternatives to architecture's typical response to flee (Figure 2). Through these analyses, the types were understood as having particular qualities that could be extrapolated as components that are temporal and able to foster indeterminacy. These studies led the projects to invent infrastructural types that could be coupled with programmatic use, for instance, by breaking and distributing the wing wall strategically (Figure 3 ). As a water management mechanism, the wing wall is meant to trap sediment and prevent erosion in river banks but dislocated as a sequence of components it might allow for various flows of water. Combined with program, these flows foster pockets of informal activity and ecology particular to speed of water and sediment collection. Thus, the manipulation of water flow relates to program and feeds into the architecture, resulting in a configuration in which the form supports a specific relationship between program and infrastructural capacity.
Continuing with the spirit of architecture and infrastructure comingling to produce unexpected formal outcomes and experiential possibilities, the following projects serve as examples of bottom-up strategies in which architecture is calibrated in conjunction with water infrastructure to manage a dynamic range of ecological and programmatic relationships. This encourages material exchanges with water during various flood states and suggests new processes and experiences. Both projects presented here attempt to find linkages and hybrids between the architecture and water infrastructure that can trigger new potentials for the ecotourism industry, one that acknowledges a necessary union between economy and ecology and which, in Suriname, tends to rely on proximity to water.

In the case of the project, Terra Pericolosa (Figure 4), the mangrove, groyne, and dike are combined with a hiking circuit. The challenge for this project was the creation of structure and system for developing the growth of the mangrove forest to protect against coastal erosion. The project proposes to pair the young mangroves with groynes in order to trap sediment and protect them while they grow. A system of loops and groynes stabilizes the mud banks which in turn absorb the forces from waves, protecting the young mangroves.

Whereas the expectations for coastal leisure are usually sunny beaches, the reality of Suriname's environment provokes an
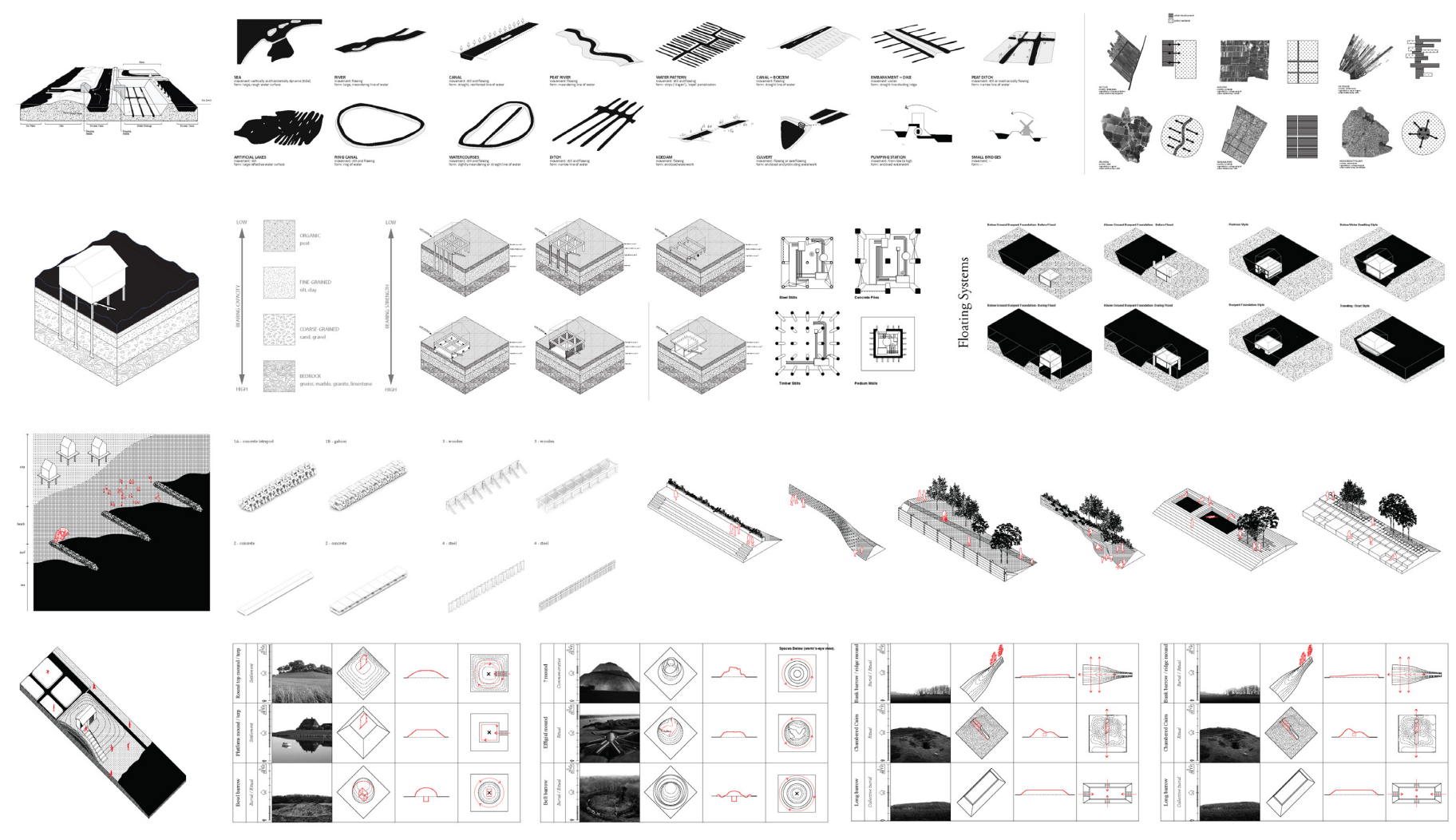

Figure 2: Water infrastructure catalog from top to bottom: polders, elevated houseing, groynes, mounds. The analytical drawings describe their functionality and methods of operation while extrapolating possible experiential and formal outcomes. Included in the analysis were: canals, culverts, dams, sea walls, swales, dikes, dunes, elevated housing, floating homes, infiltrations basins, mangroves, mounds, polders, and sluices. 


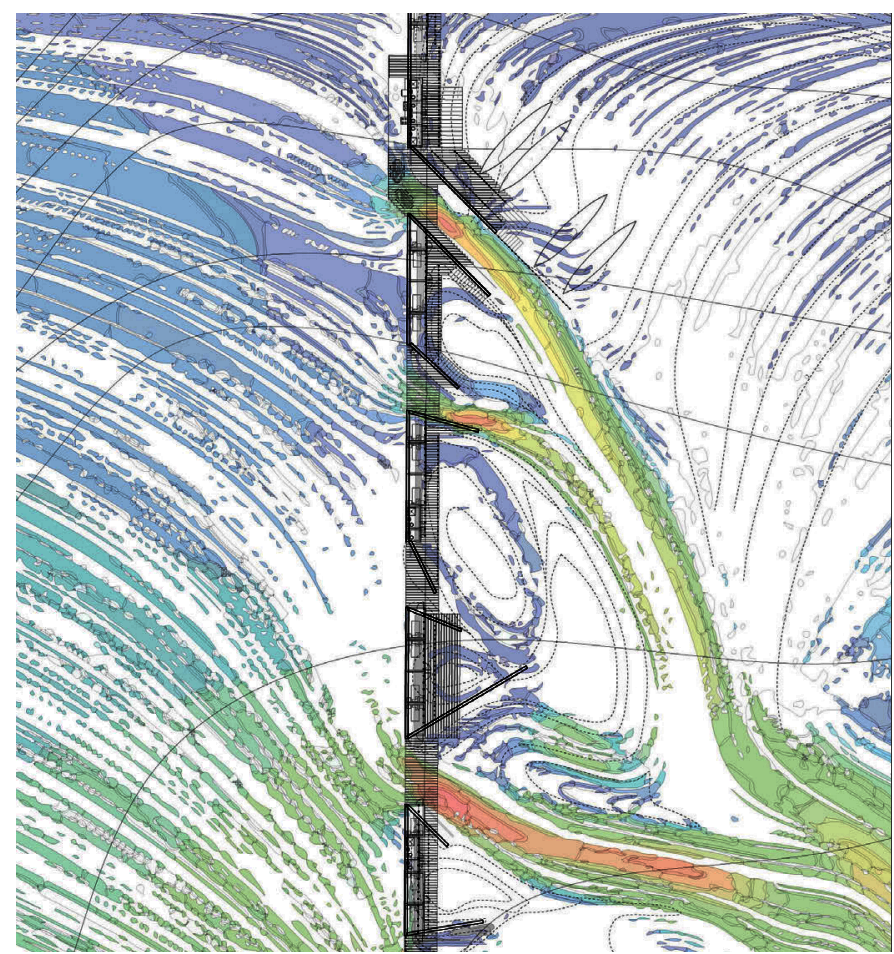

Figure 3: Architecture-infrastructure hybrid, Wing Wall plus village pier and resort. Student: Helen Lee

alternative way of experiencing the coast as a vast and austere landscape; one that might be better articulated as an accumulated experience rather than postcard image. Thus the hiking circuit serves as a method of coupling program with a structure for mangrove growth and is constructed for the use by a certain type of traveler: the adventurer.

Ultimately, the circle was found to be advantageous on both infrastructural and experiential levels: 1 ) its geometry provided efficient enclosure to support the growth of mangroves, and 2) the paths could overlap and become daisy chained together creating multiple lengths of circuit. In other words, the path was variable, allowing a traveler to walk each circle in its entirety or divert to new loops when intersections occur in order to select length of journey and level of difficulty. With this relatively simple system of paths there is an opportunity to reformat the coastal mangrove scape, providing a protective structure for growth, while also supporting and encouraging human engagement.

The path incrementally grows, using a percentage of the new mangroves to support the path, and reconstructing partially selfcontained forests in areas where the combination of sea level rise and larger scale developments have inadvertently cut off their life supply of "sweetwater" (freshwater). Currently, the dike is constructed to protect inland areas but has the negative effect of interrupting natural hydrological cycles. This is referred to locally as "the meeting of the waters" where saltwater meets fresh water. The hydrology of these wetlands is critical for providing freshwater to the coast. In response to the failure of hard infrastructure to control the boundary of water, strategic cuts are made in the dike to reintroduce the flow of sweetwater, challenging the long term viability and ecological repercussions of Suriname's dike.

The materiality of the path and its weather allows it to become a physical marker of the height of water. A patinated metal would mark the tidal shift over time, and the inclination of the paths would allow portions to be submerged while other portions elevated above the water would form new ways to move along the path. The build up over time of the site strategy follows a set of criteria including: elevational changes, viewing points orienting groynes perpendicular to coastlines, and topography determining a logic for scale, tangency, and overlap of loops with useful overlaps used for program and develop into inhabitable space. The project ultimately works from the territorial scale of coastal rehabilitation, to architectural interventions, to the detail of mechanisms that attach paths to mangrove trunks, creating a system that works with the natural formation of mangrove growth and hydrological cycles of the site.

The project Polderscape anticipates the appropriation of existing infrastructural mechanisms and constructs a system that accommodates and filters flood waters through specific and coordinated architectural insertions. Intervening in one of the many abandoned and failing polders, this project manipulates and removes sluices (mechanisms that control the flow of water from one body to another), incrementally allowed for staged flooding and mixing of inland water (fresh) with river water (tidal and brackish). From the river, the sluice is the only sign that indicates the land beyond is not virgin territory. Historic maps indicate the expansive scope of colonization, and although plantation life has been obsolete for 150 years, the palimpsests in the landscape and underlying organization are still present today but quite clearly reveal that nature is winning out as the delineations begin to blur and become obscured by forest regrowth.

The appropriation of the site and its existing mechanisms opened the door for a specific tailoring of the conditions found on site, specifically that of vegetation and regrowth as related to the found water content. In Suriname, water type has its own metric depending on the minerals, salt content, or organic matter found in the water. The manipulation of these values radically changes the water's color and quality and creates diverse habitats for varied species to grow. From this catalog of values, the project arrays and organizes plant species in the order in which they tolerate various mixes of salt and sweet water. By inserting a field of walls, filters, and sluices, a system was established that would allow control over this mixing of sweet and salt water. Yet these walls do double duty by, first, structuring the landscape into various proportions of salt to sweet water, and, second, acting as support walls for later architectural development. Thus, the sequence of wall-like objects situated on site serve a purpose not unlike James Corner's recognition that "urban infrastructure sows the seeds of future possibility, staging the ground for both uncertainty and promise. The preparation of surfaces for future appropriation differs from merely formal interest in single surface construction. It is more strategic, emphasizing means over ends, and operational logic over compositional design." ${ }^{5}$ The assemblage of walls create a 

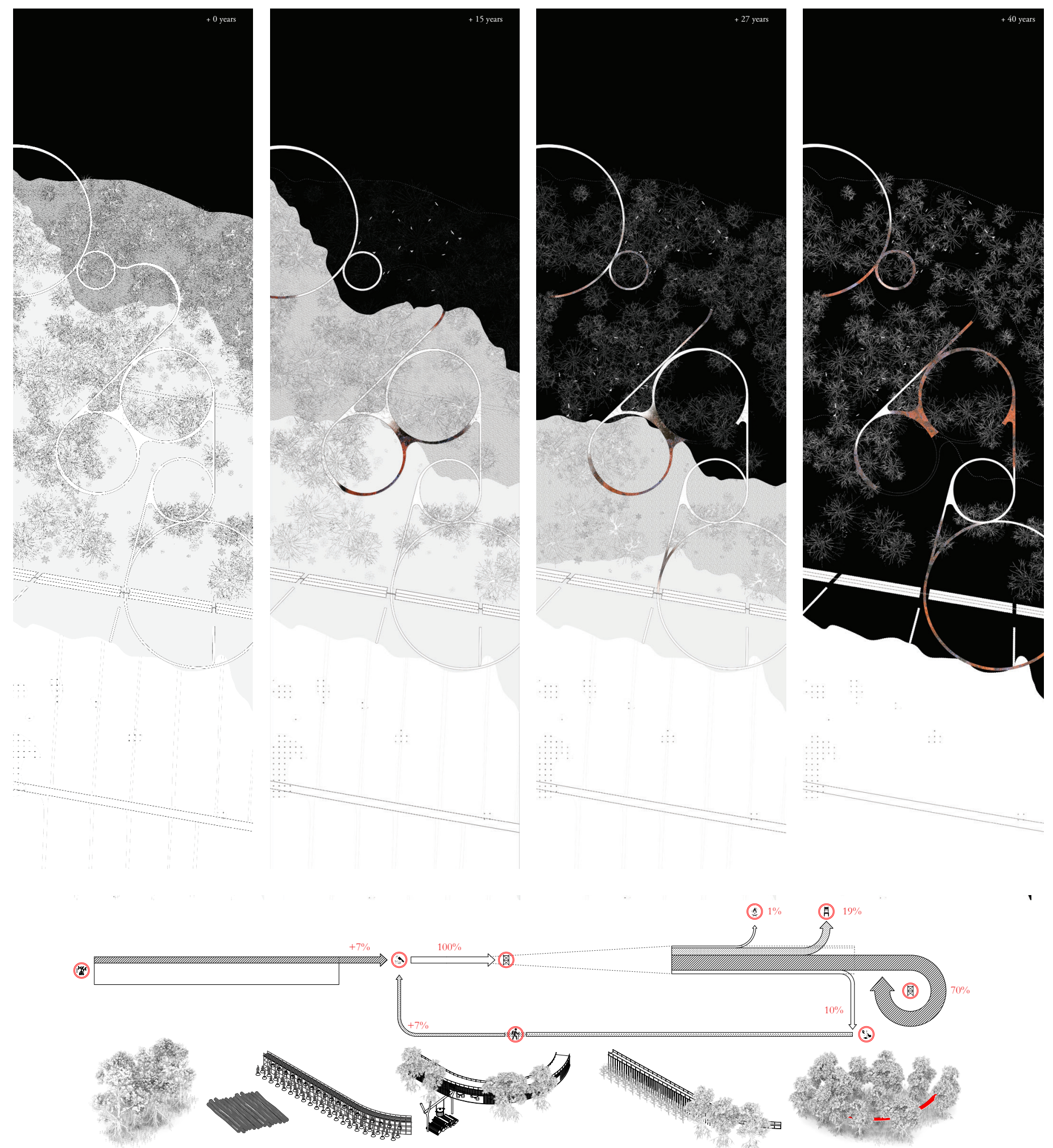
(1\%
(a)
Existing, declining mangrove fores
(2)
(日)
scaffolding to for may be harvested support paths,

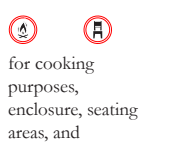
groyne structures (which trap sediment and allow for mangrove growth). Fully grown trees replace the scaffolding path system.
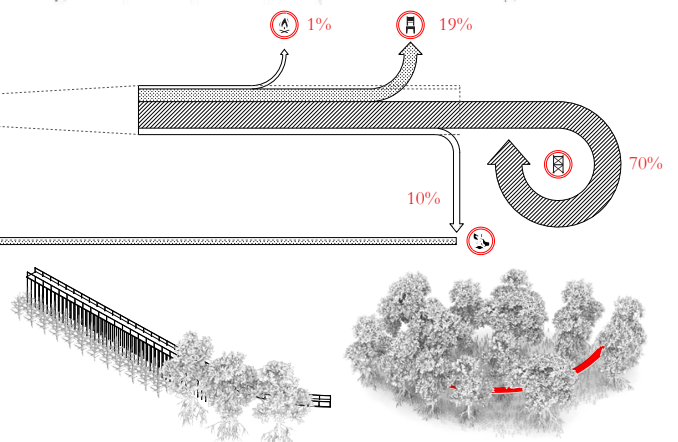

(9)

The path continues to grow $70 \%$ of the removed scaffolding is as the mangroves develop, reused to build temporary scaffolding New mangroves are $\quad$ for the next groyne + loop along the available for harvest.

Figure 4: The construction of roads and sea walls has led to the depletion of mangroves along the coast of Suriname. To facilitate the remediation of mangroves, a hiking path is constructed that establishes a framework for their growth and protection. Above, Path over time assuming sea level rise predictions. Below, Path construction and mangrove remidiation cycle. Stdents: Jessica Jiang, Aashti Miller, Beatrice Goh 


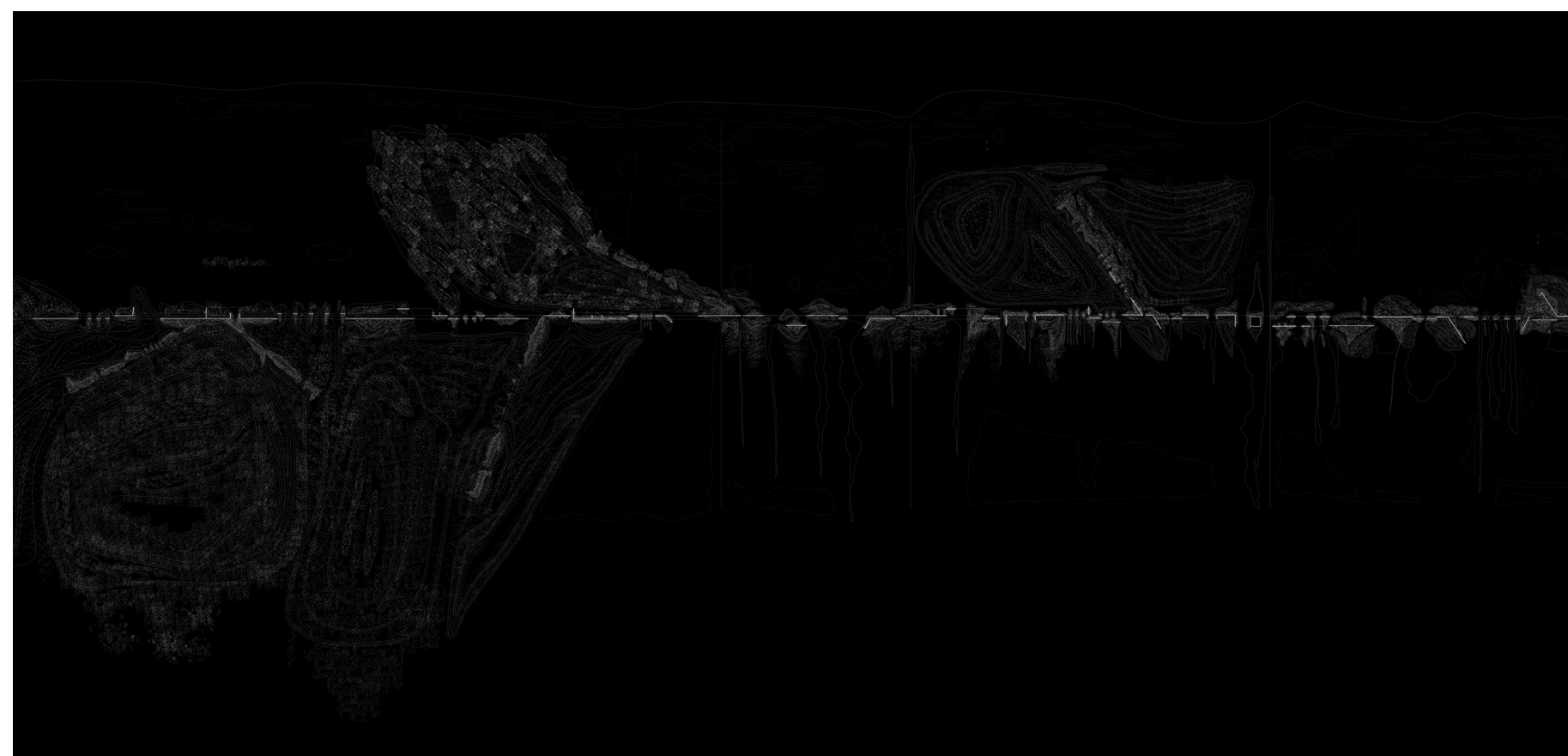

Figure 5: Partial unfolded plan of filtering wall that allow afor a variety of water levels and salt content percentages that in turn create ecological variation. Students: Min Keun Park, Lauren Lochry, Rohan Cherayil

landscape first that is ripe for dynamic change and controlled growth before becoming supports for lodging above. The result is a pathway that creates multiple micro-environments while the overlaps and junctures of walls become nodes for public use. The unfolded plan of the project reveals its purpose as a filter that generates pockets of differentiated plant life (Figure 5). By staging and calibrating flooding through a field of hybrid architectural-infrastructural objects, the project suggests that a coordinated system might both provide a set of diverse experiences while structuring the way a site accommodates flood waters.

As coastal areas become increasingly more vulnerable they are faced with two strategies according to contemporary models: to fortify or to evacuate. At the same time, architecture in remote or outlying territories adapts to sea level rise simply by rising above new, and at times arbitrary, horizons. The above projects suggest an opportunity to rethink these current strategies by suggesting that the hybridization of architecture and infrastructure might result in objects of cultural production rather than remaining isolated from one another as they are are typically conceived of today. By merging small and large scales, deterministic objects with indeterminate landscapes, and bringing experiential value through the occupation of infrastructure, Lo-Res outlines new tactics for resilience in the face of a changing climate. The proposed strategies suggest bottom-up logics with expanding scales ranging from the intensely local scale of architecture to a coordinated system of infrastructural artifacts. In considering that normative methods of flood defense render coastal areas uninhabitable or result in distorted architectural forms and experiences, Lo-Res tactics offer an alternative set of operations that produce new types of experience and habitation of a coast in flux.

\section{ENDNOTES}

_ (post)line (Figure 1) a Sponsored by the Eidlitz Travel Fellowship, Cornell University, Department of Architecture and DCA Premier Grant, Staten Island Arts, with public funding from the New York City Department of Cultural Affairs.

Work produced in Figures 2-5 are from the Cornell University Department of Architecture Option Studio, Lo-Res 2016, led by Michael Jefferson and Suzanne Lettieri.

Dutch Dikes served as instrumentlal resource for the studio: Pleijster, Eric-Jan, and Cees van der Veeken. Dutch Dikes. Rotterdam: NAI010 Publishers, 2014.

1. Dutch strategies that subscribe to a softer framework of water management have been imported to the United States with experts from Holland consulting on projects and participating in competitions such as "Rebuild by Design" and "Dutch Dialogues".

2. Post Hurricane Sandy a series of urban visions related to flooding were proposed or resurrected, including but not limited to projects put forth in Rising Currents, Structures of Coastal Resilience, Rebuilding By Design, and Design in the Terrain of Water.

3. "Federal Emergency Management Agency Base Flood Elevation," http://www. fema.gov/national-flood-insurance-program/base-flood-elevation (March 26, 2015)

4. D'Hooghe, Alexander. "The Objectification of Infrastructure." Projections 11 (2011): 85-94.

5. James Corner. "Terra Fluxus." in, The Landscape Urbanism Reader, ed. Charles Weldheim, New York, Princeton Architecture Press, 2006, p.31 